\title{
Preface to the First Volume of the First Edition.
}

The present work, as differing from the existing Shakespearian glossaries, the object of which has been only to explain what has become obsolete and unintelligible in the writings of the poet, is to contain bis whole vocabulary and subject the sense and use of every word of it to a careful examination.

As it was not intended to establish a critical standard, but only to furnish some of the necessary materials for criticism, it seemed convenient to lay aside, for the present, the question of the authenticity of the works generally ascribed to Shakespeare, and to consider as genuine all that has been commonly printed together as Shakespeare's, namely the thirty-six plays of the first and second Folios, together with Pericles, and the so called Poems; but to disregard the apocryphal pieces of the latest Folios as well as those which the criticism of still later times has brought into connection with the name of the poet. The stage-directions, too, even those of the earliest editions, have been left unnoticed, as it appeared more than doubtful whether they were written by Shakespeare himself.

In the present unsettled state of textual criticism it could not be decided, whether the Folios or the extant Quartos deserved greater credit. But fortunately the business of a lexicographer was, in this point at least, easier than that of an editor, who must make his choice between 
different lections, whereas the former may fairly content himself with registering the occurring variations. These have indeed been collated with great care wherever some authority could be attributed to the ancient texts; excluding, of course, those Quartos which the editors of the first Folio meant when speaking of stolen and surreptitious copies, maimed and deformed by the frauds and stealths of injurious impostors, namely the Quartos of the Merry Wives and Henry V, the 'First Part of the Contention', the 'True Tragedy, and the earliest impressions of Romeo and Juliet' (1597) and of Hamlet (1603). Their variations are, at the best, of the same weight as the conjectures of modern emendators.

The example and reasons of the Cambridge editors have been decisive for adopting the modern orthography, those cases excepted when the different spelling of the old editions was evidently caused by a difference of pronunciation.

As for etymology, which ought to be the groundwork of every general dictionary, its importance seemed subordinate and sometimes even doubtful in ascertaining the sense of words in a particular period, - a period especially in which the genius of the language broke new ways, now and then even with some violence, to supply its increasing wants. Therefore the derivation of words has been neglected on purpose, except when there was no other means of finding out their meaning. Accordingly, in arranging the different significations of one and the same word, a natural and rational rather than an historical order has been observed, as it always seemed the safest way to study and explain the language of Shakespeare by itself, calling in no other help as long as it could be done without. In the definitions themselves as well as in their arrangement there will undoubtedly much be found to object against, but let it at the same time be borne in mind that it is next to impossible to draw everywhere a strict line of demarcation, and that, at any rate, the means of finding the truth for himself have always been placed within the reach of the reader.

Originally a purpose was entertained of making the quotations absolutely complete, even with respect to the most common and constantly recurring parts and forms of speech. As, however, there arose some danger of impairing the utility of the book by hiding momentous 
questions under cumbrous details, copious use has been made of the signs $f . i$. and etc. by way of indicating that sufficient proof, if needed, was offered in every page of the poet.

On the other hand, it was not quite easy to resist the temptation to make this lexicon a general repertory and store-house of Shakespearian lore by collecting and garnering up in it all that the industry of two centuries had done in this branch of literature. But, for once, first thoughts were best. In pursuing too vast a project, the principal design of the work was too likely to have sometimes been lost sight of. Following, therefore, the old maxim that the half is more than the whole, and keeping within the proposed bounds, the task was limited, in whatever reached beyond them, to the smallest possible compass. Obscurities not originating in the peculiar use of words, but in the poet's train of thought, have been considered as quite out of the question and entirely left to the commentators.

Even thus the work would remain extensive enough to make any superfluity a fault. Erroneous opinions and wrong conjectures of modern editors were not admitted, unless they had become too popular to be altogether left unnoticed. Obvious and evident things, that stood in no need of authority, were left to speak for themselves; and only in doubtful cases, or if there had been some particular merit in finding the truth, it seemed unfair not to give every one his due. But after all, truth cannot fare better than to be received as a matter of course.

Foreign and dialectic words and phrases used by Shakespeare will be collected in an appendix to the second volume, for which are also reserved some grammatical remarks designed to prove the justness of several interpretations which would else, perhaps, appear arbitrary and hazardous. They are fewer in number than was at first anticipated, for the excellent Shakespearian Grammar of Mr. Abbott, published in the meantime, together with Sidney Walker's Critical Examination of the Text of Sh., reduced the task to that of a gleaner following in the footsteps of reapers and picking up a few neglected ears.

Of what use the work will be, the event is to prove; - planned it was with a view to make the poet better understood than before; - 
to lay a firmer foundation for the criticism of his text; - to furnish reliable materials for English lexicography, which has, since the time of Samuel Johnson, increased in extent rather than in intrinsic value; - to set right, although only one, yet certainly the most prominent landmark in the history of the English language.

While the general reader will look for assistance in the definitions and explanations, scholars and critics will be soonest pleased, if satisfied by the exactness of the quotations. Therefore communications concerning errata will be extremely welcome.

Merely practical considerations prevailed in choosing the English language for the interpretations. No doubt the English of a German will often be found exceptionable and try the indulgence and kindness of the reader. But the author had no greater ambition, - if a lexicographer may be allowed to be ambitious - than to be useful also to born Englishmen.

Koenigsberg in Pr., Febr. 1874.

A. SCHMIDT.

\section{Preface to the Second Volume of the First Edition.}

The Appendix of this second volume will contain, besides what has been promised in the preface of the first, a list of the Shakespearian words forming the latter part in compositions, to meet a want not only felt by the author himself on many occasions, but intimated to him by some literary friends. In applying to it, it must always be borne in mind that it pretends to no higher claim than to be a supplement to this dictionary, and has no other object than to complete the quotations of the respective articles, by setting before the reader the whole range 